\title{
Analysis of Spatial Characteristics and Influence Factors of BeiJing-TianJin-Hebei Urban Agglomeration
}

\author{
Yuehui Liu ${ }^{1 *}$ \\ ${ }^{1}$ School of economics and management, Beijing Jiaotong University, Beijing, 100089, China \\ *Corresponding author. Email: liuyuehui14@163.com
}

\begin{abstract}
This paper selected BeiJing-TianJin- Hebei urban agglomeration which includes Beijing,Tianjin and 11 cities of Hebei province as the object of study.Based on the data of population,GDP and mutual distances of 2012,2014 and 2016,this paper built a modified gravitational model to analyze the density,point centrality and the core- peripheral structure of the agglomeration by social network analysis. The result indicates that the density of BeiJing-TianJin- Hebei urban agglomeration is increasing year by year,but still at a low level.The unblanced structure of the urban agglomeration is being improved gradually. At last, QAP regression analysis will be applied to the analysis of influence factors of agglomeration's network structure to verify that the innovation of traffic,the upgrading of industries and the level of economic globalization will influence the spatial structure of urban agglomeration.
\end{abstract}

Keywords: BeiJing-TianJin- Hebei, urban agglomeration, social network analysis, QAP regression

\section{INTRODUCTION}

According to Fang[1],urban agglomeration refers to the formation of a compact spatial organization and close economic ties in a specific area, with more than one mega city as the core and at least three large cities as the unit, relying on a developed infrastructure network such as transportation and communication, which finally achieve a highly urbanized and highly integrated urban group.Today,urban agglomeration breaks administrative boundaries and participates in the course of urbanization and economic development in a new spatial form. The urban agglomeration has been launched as the main body globally competition for units. Of the world's six major urban agglomerations, the GDP of the Yangtze River Delta urban agglomeration accounts for $20.5 \%$ of the national GDP; according to Liu and Zhang[2], the US Boswah urban agglomeration has gathered $20 \%$ of the American population and $30 \%$ of the manufacturing output value. Japan's Pacific coast urban agglomeration brings together $80 \%$ of the country's high-tech industries.

The Beijing-Tianjin-Hebei urban agglomeration includes 14 municipalities, namely Beijing and Tianjin, 11 prefecture-level cities in Hebei Province, and Anyang City in Henan Province. The total GDP of the Beijing-TianjinHebei urban agglomeration ranks second in the national urban agglomeration, after the Yangtze River Delta urban agglomeration; the per capita GDP ranks third in the national urban agglomeration, after the Pearl River Delta urban agglomeration and the Yangtze River Delta urban agglomeration. With the development of the BeijingTianjin-Hebei coordinated development strategy as a national strategy, especially after Anyang was included in the Beijing-Tianjin-Hebei urban agglomeration in 2016, the GDP of the Beijing-Tianjin-Hebei urban agglomeration reached 75,62.5 billion RMB, accounting for $10.44 \%$ of the national GDP of the year The group's overall GDP increased by $8.56 \%$ over 2015 . At the same time, the industrial structure of Beijing, Tianjin and Hebei has been further optimized. In 2015, the tertiary industry in Beijing was as high as $90.6 \%$; the proportion of the tertiary industry in Tianjin exceeded $50 \%$ historically. The proportion of the tertiary industry in Hebei Province has also increased significantly. Although the proportion of the tertiary industry is still lower than that of the secondary industry, it has exceeded the $40 \%$ mark for the first time.

However, compared with other urban agglomerations, the Beijing-Tianjin-Hebei urban agglomeration has a large gap in both the level of urbanization and economic development. Although the per capita GDP of the BeijingTianjin-Hebei urban agglomeration ranks third in the country's urban agglomerations, the gap between the Beijing-Tianjin-Hebei urban agglomeration and the Yangtze River Delta and the Pearl River Delta urban agglomerations is very wide, with specific values of 29930 RMB and 48074 RMB respectively. In 2016, the urbanization rate of the permanent population in the Pearl River Delta urban agglomeration reached $84.3 \%$, and the urbanization rate of the permanent population in the Yangtze River Delta urban agglomeration was $68 \%$, while the Beijing-Tianjin-Hebei urban agglomeration only had $58 \%$.

Scholars have also conducted a series of studies on urban agglomerations.Hou et al.[3]firstly performed a social network analysis on the economic structure of the Yangtze River Delta urban agglomeration with the help of modified gravity models in 2009. The study found that the degree of integration of the Yangtze River Delta urban agglomeration is not high.But when $\mathrm{Li}[4]$ doing the same analysis in 2011, the results show that the economic network of the Yangtze River Delta urban agglomeration 
has reached a medium scale. Lu et al. [5] selected data from the Beijing-Tianjin-Hebei urban agglomeration in 2006 and 2012, and concluded that the economic network structure of the Beijing-Tianjin-Hebei urban agglomeration is showing rapid growth.Guan and Liu[6],Tang et al[7] and Liu[8] all came to the same conclusion that the development within the BeijingTianjin-Hebei urban agglomeration is unbalanced. Lu[9] proposed the path to optimize the urban agglomeration from functional division and economic connection.

In summary, the scholars' research on urban agglomerations across the country is relatively complete. However, after the coordinated development of BeijingTianjin-Hebei in 2016 rose to the national strategy, few scholars have paid attention to the structural changes of urban agglomerations before and after policy changes. Therefore, the span of our data selection includes the timing of policy changes and more comprehensive social network analysis indicators have been used to measure the spatial structure of the Beijing-Tianjin-Hebei urban agglomeration.

\section{ANALYSIS ON THE SPATIAL STRUCTURE OF BEIGING-IANJIN-HEBEI URBAN AGGLOMERATION}

\subsection{Model Design}

Newton's formula of universal gravitation reflects the magnitude of interaction forces between objects, and has now been widely used in geography, economics, and psychology. The world's first application of the gravity model to the analysis of the interaction between cities was Harvard's professor Zifu, who established a paradigm for analyzing the interaction between cities using the gravity model. The calculation formula of the gravity model in this paper is:

$$
\boldsymbol{R}_{i j}=\frac{\sqrt{P_{i} V_{i}} * \sqrt{P_{j} V_{j}}}{D^{2}{ }_{i j}}
$$

Rij represents the value of the connection between cities $\mathrm{i}$ and $\mathrm{j}$. $\mathrm{Pi}$ and $\mathrm{Pj}$ is the population of city $\mathrm{i}$ and city $\mathrm{j}$, the unit is 10,000 people. $\mathrm{Vi}$ and $\mathrm{Vj}$ is the comprehensive strength of the two cities, measured by the GDP of each city. D2ij is the shortest road distance $(\mathrm{km})$ between the two cities.

We obtained the population and GDP of Beijing, Tianjin and all the cities in Hebei Province through the Beijing Statistical Yearbook, Tianjin Statistical Yearbook and Hebei Statistical Yearbook in 2017, 2015, and 2013. And then we calculated the shortest road distance between two cities with the help of ARCGIS.

\subsection{Indicator Selection}

\subsubsection{Network Density}

The network density in the figure refers to the closeness of connections between the points and the degree of density of the overall connection between cities reflected in the spatial structure of urban agglomeration. The more connections there are between points in the graph, the greater the overall network density. Therefore, the more elements flow between cities within an urban agglomeration, the higher the density of the entire urban agglomeration network.

\subsubsection{Point Centrality}

Centrality is a measure of the degree to which members of an urban agglomeration are central in the system and the amount of rights they have. When measuring centrality, the indicators used in this paper are out-degree,in-degree and betweenness centrality. The in-degree actually reflects the degree to which the city is affected by other cities and out-degree is expressed as the city's influence degree on other cities. Betweenness centrality reflects the degree to which a city connects or mediates other cities.

\subsubsection{The Core-Peripheral Structure}

Core-peripheral structure analysis is to explore which cities are at the core of the system and which cities are at the periphery of the system in a regional economic system. With the continuous development of the core-periphery structure theory in recent years, there are not only core cities, peripheral cities but also semi-peripheral cities in the urban agglomeration system. Therefore, it is necessary for us to analyze the status of the cities within the BeijingTianjin-Hebei urban agglomeration and if any change has occurred in the hierarchical structure system of the Beijing-Tianjin-Hebei urban agglomeration.

\subsection{The empirical results}

The overall network density calculated by UCINET software in 2012, 2014 and 2016 is shown in Table1.

Table 1 Network density results

\begin{tabular}{ll}
\hline year & Density \\
\hline 2012 & 0.3718 \\
2014 & 0.3910 \\
2016 & 0.4103 \\
\hline
\end{tabular}

The overall network density of the Beijing-Tianjin-Hebei urban agglomeration in 2016, 2014, and 2012 were 0.4103 , 0.3910 and 0.3718 respectively. In 2014, the network density increased by $5.2 \%$ compared to 2012 , and in 2016 , 
the network density increased by $5 \%$ compared to 2014 . . The increase in the density of urban agglomerations reflects that the connection between members continue to strengthen and the level of integration continues to increase.

Compared with the Yangtze River Delta and Pearl River Delta urban agglomerations, the overall network density of the Pearl River Delta and Yangtze River Delta urban agglomerations in 2016 were 0.91 and 0.86 respectively. The network density of the Beijing-Tianjin-Hebei urban agglomeration is far from its comparison, which indicates that the links between group members are still relatively weak and the level of integration is still low.

The out-degree, in-degree and betweenness centrality of the Beijing-Tianjin-Hebei urban agglomeration calculated by UCINET are respectively shown in Table2, Table 3 and Table4.

Before explaining the results, let me explain the abbreviations corresponding to each city.

BJ-Beijing TJ-Tianjin SJZ-Shijiazhuang TS-Tangshan CZ-Cangzhou BD-Baoding LF-Langfang XT-Xingtai

HD-Handan ZJK-zhangjiakou HS-Hengshui

CD-Chengde QHD-Qinhuangdao

Table 2 Out-degree results

\begin{tabular}{ccccccc}
\hline & \multicolumn{4}{c}{ out-degree } & \multicolumn{2}{c}{$\mathbf{2 0 1 6}$} \\
\hline & value & rank & value & rank & value & rank \\
1 & 12 & BJ & 12 & BJ & 12 & BJ \\
2 & 12 & TJ & 12 & TJ & 12 & TJ \\
3 & 7 & SJZ & 8 & SJZ & 8 & SJZ \\
4 & 7 & TS & 7 & TS & 7 & BD \\
5 & 6 & CZ & 7 & CZ & 7 & CZ \\
6 & 6 & BD & 6 & BD & 7 & TS \\
7 & 4 & LF & 5 & LF & 5 & LF \\
8 & 2 & XT & 2 & XT & 3 & HD \\
9 & 2 & HD & 2 & HD & 2 & XT \\
10 & 0 & ZJK & 0 & ZJK & 1 & HS \\
11 & 0 & HS & 0 & HS & 0 & ZJK \\
12 & 0 & CD & 0 & CD & 0 & CD \\
13 & 0 & QHD & 0 & QHD & 0 & QHD \\
\hline
\end{tabular}

From the perspective of out-degree, Beijing and Tianjin both have a value of 12 , which is the lines starting from Beijing and Tianjin in the social network diagram are connected to the other 12 cities, indicating that they can influence all the other members.

Table 3 In-degree results

\begin{tabular}{ccccccc}
\hline \multicolumn{9}{c}{ in-degree } & \multicolumn{2}{c}{$\mathbf{2 0 1 6}$} \\
\hline & value & rank & value & rank & value & rank \\
1 & 6 & SJZ & 6 & SJZ & 7 & SJZ \\
2 & 6 & BJ & 6 & BJ & 6 & BJ \\
3 & 6 & TJ & 6 & TJ & 6 & TJ \\
4 & 6 & BD & 6 & BD & 6 & BD \\
5 & 6 & CZ & 6 & CZ & 6 & CZ \\
6 & 5 & LF & 6 & LF & 6 & LF \\
7 & 5 & HS & 5 & HS & 6 & HS \\
8 & 4 & XT & 4 & XT & 5 & XT
\end{tabular}

$\begin{array}{ccccccc}9 & 4 & \text { HD } & 4 & \text { TS } & 4 & \text { TS } \\ 10 & 3 & \text { CD } & 4 & \text { HD } & 4 & \text { HD } \\ 11 & 3 & \text { QHD } & 3 & \text { CD } & 3 & \text { CD } \\ 12 & 2 & \text { TS } & 3 & \text { QHD } & 3 & \text { QHD } \\ 13 & 2 & \text { ZJK } & 2 & \text { ZJK } & 2 & \text { ZJK }\end{array}$

From the point of in-degree, Shijiazhuang ranked the highest in all the years, rising from 6 in 2012 to 7 in 2016, indicating that Shijiazhuang was influenced by 7 memebers. Other cities, such as Beijing, Tianjin, Baoding, Cangzhou and Langfang, have an in-degree of 6 over the years, indicating that these cities are influenced by 6 other cities.

Table 4 Betweenness centrality results

\begin{tabular}{ccccccc}
\hline \multicolumn{7}{c}{ betweenness centrality } \\
& \multicolumn{2}{c}{$\mathbf{2 0 1 2}$} & \multicolumn{2}{c}{$\mathbf{2 0 1 4}$} & \multicolumn{2}{c}{$\mathbf{2 0 1 6}$} \\
\hline & value & rank & value & rank & value & rank \\
1 & 21 & SJZ & 21 & SJZ & 30 & SJZ \\
2 & 18 & BJ & 14 & BJ & 15 & BJ \\
3 & 18 & TJ & 14 & TJ & 15 & TJ \\
4 & 1.75 & BD & 2 & CZ & 2.25 & CZ \\
5 & 1.75 & CZ & 1.33 & TS & 1.92 & BD \\
6 & 0 & ZJK & 1 & LF & 1.33 & TS \\
7 & 0 & HD & 1 & BD & 1.25 & LF \\
8 & 0 & LF & 0 & ZJK & 0.5 & XT \\
9 & 0 & CD & 0 & CD & 0.25 & HD \\
10 & 0 & QHD & 0 & QHD & 0 & ZJK \\
11 & 0 & HS & 0 & HS & 0 & HS \\
12 & 0 & XT & 0 & XT & 0 & CD \\
13 & 0 & TS & 0 & HD & 0 & QHD \\
\hline
\end{tabular}

Shijiazhuang is the city with the highest betweenness centrality, followed by Beijing and Tianjin. It indicates that Shijiazhuang is the most important bridges in its urban agglomerations.

The core-peripheral structures of 2012 and 2014 are the same. However, in the core-periphery structure of 2016, although the core cities Beijing and Tianjin have not changed, Shijiazhuang, Baoding, Langfang, and Cangzhou in Hebei Province have become semi-peripheral cities. They have already stood out from other cities in Hebei, and have begun to drive the development of other cities in Hebei, occupying an increasingly important position in the development of the urban agglomeration.

\section{ANALYSIS OF FACTORS AFFECTING THE SPATIAL STRUCTURE OF BEIJING-TIANJIN-HEBEI URBAN AGGLOMERATION}

\subsection{Method}

Because the traditional econometric analysis uses attribute data, the requirements for the data are independent of each other, otherwise the regression analysis will have serious multicollinearity and cause errors in the results. When studying the influencing factors of the Beijing-TianjinHebei urban agglomeration, the data is relational data, 
which does not meet the requirements of traditional econometric analysis methods. Therefore, we chose the non-parametric method commonly used in social network analysis methods-QAP (Second Assignment Procedure) to study the influencing factors.

QAP correlation analysis gives the correlation coefficient between matrices by comparing the corresponding elements of the two matrices. QAP regression analysis is to explore the regression relationship between multiple independent variable matrices and one dependent variable matrix.

\subsection{Indicator Selection}

Four factors have been chosen to do the QAP analysis, they are factor agglomeration and diffusion, economic globalization, transportation innovation and industrial structure upgrading.

We use the total social fixed asset investment of each city as the index value of factor agglomeration and diffusion; the actual use of foreign investment to reflect the globalization of the city; transportation innovation is replaced by high-speed rail or trains between cities. If there are high-speed rails between cities, the value is recorded as 1 , otherwise it is recorded as 0 ; the industrial structure upgrading is replaced by the difference between the tertiary industry and the secondary industry in each city. Except for transportation innovation, other indicators are replaced by the difference matrix between cities.

\subsection{Results of QAP Analysis}

Table 5 QAP correlation analysis results

\begin{tabular}{cccc}
\hline indicators & correlation & significance & standard deviation \\
\hline Factor agglomeration and diffusion & 0.256 & 0.094 & 0.169 \\
Economic globalization & 0.365 & 0.003 & 0.142 \\
Innovation of transportation & 0.382 & 0.015 & 0.165 \\
Industrial structure upgrading & 0.304 & 0.032 & 0.175 \\
\hline
\end{tabular}

The results of QAP correlation analysis in table 5 show that factor agglomeration and diffusion, economic globalization, transportation innovation and industrial structure upgrading all have positive correlations with the spatial network of the Beijing-Tianjin-Hebei urban agglomeration, and the correlation coefficients are 0.256 , $0.365,0.382$ and 0.304 , indicating that these four indicators can promote the improvement of the network structure of the Beijing-Tianjin-Hebei urban agglomeration.

Table 6 QAP regression analysis results

\begin{tabular}{cccc}
\hline indicators & Unstandardized Coefficients & Standardized coefficient & significance \\
\hline $\mathbf{c}$ & 0.0968 & 0 & \\
Factor agglomeration and diffusion & 0.1782 & 0.1350 & 0.154 \\
Economic globalization & 0.1977 & 0.1993 & 0.015 \\
Innovation of transportation & 0.2852 & 0.2896 & 0.015 \\
Industrial structure upgrading & 0.2880 & 0.1958 & 0.050 \\
\hline
\end{tabular}

The overall model's decision coefficient $R^{2}=0.278$, that is the model explained the spatial connection matrix of the Beijing-Tianjin-Hebei urban agglomeration matrix at $27.8 \%$ and the regression of the model was significant.

At a significance level of 5\%, the coefficients of economic globalization, transportation innovation and industrial structure upgrading are very significant, indicating that these factors have a positive impact on the spatial connection matrix of the Beijing-Tianjin-Hebei urban agglomeration. Therefore, the higher the level of transportation innovation, economic globalization and industrial upgrading, the closer and stronger the spatial connections between the Beijing-Tianjin-Hebei urban agglomerations.

Among the regression analysis results, the industrial structure upgrading has the greatest impact on the spatial connections of the urban agglomeration among all the factors, followed by the innovation of transportation and economic globalization has the least impact.

The effect of the accumulation and diffusion of factors on the spatial structure of the Beijing-Tianjin-Hebei urban agglomeration is not significant.One explaination for this is that Beijing and Tianjin are particularly attractive for resource elements, resulting in a highly uneven distribution of elements.

\section{CONCLUSIONS AND SUGGESTIONS}

This paper uses social network analysis to analyze the spatial network structure of the Beijing-Tianjin-Hebei urban agglomeration and the conclusions are as 
Model, Journal of Yanshan University, 2017, vol.18, pp. 80-87.

still at a low level compared with other urban agglomerations. What's more, Beijing and Tianjin have the greatest impact on other memebers and Shijiazhuang is the most important intermediary city.In 2016, Shijiazhuang, Baoding, Cangzhou, and Langfang of Hebei were separated from peripheral cities to semi-peripheral cities.

In addition, through QAP analysis and research, the factors affecting the spatial structure of the Beijing-Tianjin-Hebei urban agglomeration are: industrial structure upgrading, transportation innovation and economic globalization.

So the corresponding suggestions are as followed. Firstly, Beijing-Tianjin-Hebei urban agglomeration should promote the orderly transfer of industries steadily. And then, a smooth and intelligent transportation system must be established as soon as possible in Beijing-Tianjin-Hebei urban agglomeration. Finally, Hebei should seize the opportunity to strengthen the construction of the new national zone- Xiong'an.

\section{REFERENCES}

[1] C.L.Fang, Important Progress Made in China's Urban Agglomerations and Future Development, Acta Geographica Sinica, 2014, vol.69, pp. 1130-1144.

B.H.Hou, Z.B.Liu, Z.G.Yue, Social Network Analysis of the Regional Economic Integration in the Yangtze River Delta, China Soft Science, 2009, vol.12, pp. 90 101.

[2] C.B.Liu, C.Zhang, A Comparative Study of the Boswah City Group and the Beijing-Tianjin-Hebei City Group, City Observation, 2009,vol.1, pp. 63-69.

[3] B.H.Hou, Z.B.Liu, Z.G.Yue, Social Network Analysis of the Regional Economic Integration in the Yangtze River Delta, China Soft Science, 2009, vol.12, pp. 90 -101.

[4] X.Li, Research on the Economic Network Structure of the Yangtze River Delta Urban AgglomerationAnalysis from the Perspective of Social Network, Journal of Shanghai University of Finance, 2011, vol.4, pp. $105-114$.

[5] J.P.Lu, Z.W.Yang, Y.Liu, Research on the Economic Contact Network of Beijing-Tianjin-Hebei Urban Agglomeration, Exploring Economic Issues, 2015, vol.2, pp. 117-122.

[6] X.G.Guan, C.L.Tang, G.H.Zhou, Analysis of Spatial Relations of Beijing-Tianjin-Hebei Urban Agglomeration Based on Modified Gravity Model, Urban Issues, 2014, vol.11, pp. 21-26.

[7] Z.S.Tang, P. Lu, S.Y.Fan, S.S.Deng, Research on Spatial Economic Relations of Beijing-Tianjin-Hebei Urban Agglomeration— Based on Modified Gravity
[8] J.Z.Liu, Research on the Coordinated Development of Industrial Optimization and Urban Evolution in Beijing-Tianjin-Hebei Urban Agglomeration, Hebei University of Technology, 2013.

[9] P.Lu, Research on Optimization of Spatial Structure of Beijing-Tianjin-Hebei Urban Agglomeration, Yanshan University, 2017.

[10] Dematteis G, Globalisation and regional integration: The case of the Italian urban system, GeoJournal, 1997, vol.43, pp.331-338.

[11] D.Zhou, Research on the Spatial Flow of Financial Resources in the Yangtze River Delta City Group, Shanghai Economic Research, 2016, vol.12, pp. 69-79.

[12] D.L.Wang, Characteristics of the Industrial Structure Evolution of the Beijing-Tianjin-Hebei Urban Agglomeration, Chinese Collective Economy, 2018, vol.6, pp. 34-35.

[13] Friedmann J, Miller J, The urban field, Journal of the American Institute of Planners, 1965, vol.31, pp.312-319.

[14] J.Z.Liu, S.Y.Gao, Research on the Spatial Relations of Beijing-Tianjin-Hebei Urban Agglomeration Based on Urban Connection Intensity and Urban Flow, Regional Research and Development, 2013, vol.32, pp. 57-61.

[15] S.B.He, H.W.Wang, Research on the Spatial Structure of Beijing-Tianjin-Hebei Urban Agglomeration, Exploring Economic Issues, 2015, vol.6, pp. 105-111.

[16] W.W.Xie, H.B.Deng, H.Liu, Research on the Characteristics of Urban Innovation Network Structure of the Yangtze River Delta City Group from the Perspective of Green Development, Science and Technology Progress and Countermeasures, 2017, vol.34, pp. 52-59.

[17] Z.Zhao, J.H.Wang, J.Feng, Spatial Linkages and Impact Measurements of Core Cities in Beijing-TianjinHebei Urban Agglomeration, Economic geography, 2017, vol.37, pp. 60-66. 